Article

\title{
Sustainable Development of Employability of University Students Based on Participation in the Internship Promotion Programme of Zhejiang Province
}

\author{
Yujuan Chen ${ }^{1}$ and Ning Gan ${ }^{1,2, *}$ \\ 1 Research Center for Education Management and Policies, Ningbo University, Ningbo 315211, China; \\ chenyujuan@nbu.edu.cn \\ 2 Key Laboratory of Advanced Mass Spectrometry and Molecular Analysis of Zhejiang Province, \\ Institute of Mass Spectrometry, School of Material Science and Chemical Engineering, Ningbo University, \\ Ningbo 315211, China \\ * Correspondence: ganning@nbu.edu.cn
}

check for

updates

Citation: Chen, Y.; Gan, N.

Sustainable Development of

Employability of University Students

Based on Participation in the

Internship Promotion Programme of

Zhejiang Province. Sustainability 2021,

13, 13454. https://doi.org/10.3390/

su132313454

Academic Editors: Nnamdi

O. Madichie and Paul Agu Igwe

Received: 1 November 2021

Accepted: 3 December 2021

Published: 5 December 2021

Publisher's Note: MDPI stays neutral with regard to jurisdictional claims in published maps and institutional affiliations.

Copyright: (c) 2021 by the authors. Licensee MDPI, Basel, Switzerland. This article is an open access article distributed under the terms and conditions of the Creative Commons Attribution (CC BY) license (https:/ / creativecommons.org/licenses/by/ $4.0 /)$.

\begin{abstract}
In the context of severely restricted employment opportunities, undertaking an internship is an important way for students to enhance their employability and sustainable development. The aim of this study was to judge if the implementation of the Internship Promotion Programme (IPP) at universities in Zhejiang Province, China, could enhance graduates' employability. We conducted surveys and interviews with 400 students and 100 business executives who participated in the IPP during the past 6 years. Based on the collected data and statistical analysis, the findings show that internships help students to improve their innovative thinking, interpersonal communication abilities (domestic and international), problem-solving skills, value creation and responsibility. Participants in the IPP were compared with students who did not take part. The results demonstrated that the IPP participants exhibited higher capabilities to perform important workplace tasks and that as a result, they became more attractive to employers. The analysis, therefore, demonstrates a positive correlation between the internship experience and employability. As a result, it can be concluded that the IPP improves students' employability and is beneficial to enhancing the quality of higher education, and hence the sustainable development of students.
\end{abstract}

Keywords: higher education; internship promotion programme; employability; Zhejiang Province

\section{Introduction}

The sustainable development of high-quality education is pursued by all countries [1]. An effective method to achieve this objective is to have students participate in internships that improve their skills and enhance their learning experiences in real-world environments related to their planned careers [2]. In most cases, students complete internships prior to their academic graduation [3]. Internships during higher education are considered to be an important goal pursued by government education ministries in many different countries [4]. The standard of internships exerts an important impact on the quality of higher education institutions, but also bring certain challenges. For example, without a complete training system for internships, schools and enterprises cannot plan, arrange and guide internship work well. After a few months, interns will feel that they can not learn the professional knowledge and other content they want to learn. The implementation of internship programmes can be influenced by numerous issues such as the dynamic diversity of academics and different kinds of higher education institutions, as well as various other economic and socio-cultural factors. Duong [3] pointed out that the evaluation of higher education can be divided into five dimensions: internship level, recruitment level, social recognition, professional level of teachers and financial investment. Because of their evident importance, internships have caught the attention of many scholars and have been the subject of extensive previous research. 
Currently, the employment situation in China is very challenging. In particular, with the economic downturn following the outbreak of COVID-19, the employment rate of university graduates has dropped from $97 \%$ in 2018 to around $80 \%$ in 2020. Meanwhile, due to continuing enterprise transformation and upgrading, some employers are setting increasingly high standards for graduates, such as demanding strong problem-solving capabilities, highly developed team-working and critical thinking skills, and the ability to create value for the enterprise. Meanwhile, students also hope to exhibit stronger employability and achieve sustainable development in their careers. At present, there is an obvious gap between employers' expectations and the abilities students tend to acquire during higher education. Therefore, there is a need for a broad range of high-quality internships to help bridge this gap. However, many employers do not provide an ideal setting for students to undertake internships as the resources available to support such work placements are limited due to issues such as regulatory constraints.

Until now, 81 institutions in Zhejiang Province, China, have implemented the Internship Promotion Programme (IPP) over the past six years. This has involved a series of joint activities by enterprises and students to improve students' workplace skills and employability. Many previous studies have shown that the IPP provides valuable practical opportunities for students to develop their job application skills and employment abilities. This study aims to build on the existing research by finding out how the IPP, by providing a platform for the integration of resources from industry and higher education and supporting small and medium-sized enterprises to promote the integration of work and study. Moreover, the study aims to uncover if the IPP can improve students' employability and enhance their ability to find suitable jobs. In the study, we conducted surveys and interviews with 400 students and 100 business executives who participated in the IPP to assess its effects and the contributory factors. We also hoped to confirm the important role and value of the IPP in relation to employability, particularly concerning its effects on improving students' innovative thinking, interpersonal communication abilities (domestic and international), problem-solving skills, value creation and responsibility. By investigating the IPP, we aim to improve our understanding of the importance of internships for the continuing development of students' abilities, especially the skills that enhance their employability. The basic research process was as follows: Firstly, we collected, analysed and studied information and cases concerning the main internship activities which are implemented in the universities of Zhejiang Province, China. Secondly, the internships available in enterprises, especially the integration of higher education internships with industry, are discussed. Finally, we draw our conclusion.

\section{Literature Review}

\subsection{Promotion of Employability through Internships}

According to many previous studies [4-15], a range of factors relating to students' accomplishments during university are used to evaluate their future employability. These include academic literacy and cross-cultural communication. In order to deal with the employment challenges of college students, the Chinese government has implemented a number of policies to encourage universities to develop Internship Promotion Programmes (IPP), to mobilise enterprises to provide more high-quality internship positions and to enhance the effectiveness and quality of internships. Many outcomes revealed in prior research allow us to conclude that internship programmes improve students' employability [11-15]. However, it is also apparent that the internships offered by different enterprises result in significantly different outcomes. Zayed [16] found that the IPP requires enterprises to actively participate in internships, provide high-quality positions for students, improve their employability and raise the overall quality of the higher education sector. Moreover, the capabilities that are cultivated during internships, such as practical working ability, leadership decision-making, communication, critical thinking, etc., also promote the sustainable development of students' careers. Some studies have shown that in many universities, there is no significant difference in the employability between students who 
have participated in the IPP and those who have not, due to the lack of relevance of some of the internships which are offered to students, the unwillingness of certain enterprises to fully participate in the programme and due to many internships lasting for less than six months, which is often deemed the minimum amount of time which students need to gain tangible benefits. Therefore, it is apparent that the relevance, duration and commitment that enterprises are willing to devote to internships play a crucial role in improving the competitiveness of students in the job market and the sustainable development of their careers [17-20].

To date, numerous scholars have tried to analyse the relationship between internships and students' academic studies. To this end, researchers have designed questionnaires, built data models and utilised a series of statistical methods in an attempt to reveal the relationship. In a recent study [21], it was found that while undertaking an internship tends to improve a student's academic studies, it can also have some adverse effects. Specifically, such a situation was found with Columbia University's "Entry to Practice Programme". Although the programme was found to be effective in improving students' skills such as their leadership, innovation ability and interpersonal communication, etc., students found that due to the pressure of their university studies and their limited time for additional activities that they were not able to fully participate in their internships and therefore that they were unable to derive the full benefits such placements could potentially provide. Thus it is vital to consider the balance between internships and academic study and to consider practical hindrances to students undertaking internships.

\subsection{The Internship Promotion Programme in Universities in Zhejiang Province}

In Zhejiang Province, many universities began to implement the Internship Promotion Programme after the 1990s [18]. Recently, graduate unemployment has increased due to issues such as an inability among many graduates to adapt to the intense overtime working that is often required by companies in contemporary China (such as the infamous "996" working pattern, i.e., 9 am to 9 pm, 6 days-a-week). The main reason for unemployed graduates to do with the mismatch between the number of people graduating from universities in China and the number of graduate positions that are available, i.e., it is linked to the massive expansion of higher education enrolment that occurred in the late 1990s and the effect of this reform creating an imbalance between graduate supply and demand. Furthermore, the phenomenon of unemployed graduates has recently been compounded by the economic slowdown caused by the COVID-19 pandemic [19]. Taken together these factors are causing educational institutions to pay more attention to the content and effectiveness of the IPP and the internships which they offer, to strengthen their provision of ethics education and the professional quality of students, so as to enhance students' workplace adaptability and to prevent any further decline in the graduate employment rate [20].

Zhejiang is an economically developed province on the east coast of China. It has a long history of providing internships during higher education and is renowned for promoting innovation or entrepreneurship [21]. In Zhejiang, many measures have been implemented to improve the quality of internships. These include the development of an internship education management system and the expansion of the range of internship resources and channels through which they are available. The Zhejiang provincial government has also encouraged many powerful and successful enterprises to actively participate in the IPP and to collaborate with universities and colleges (including companies from the Fortune Global 500 and many local high-tech enterprises) [22].

A graduate survey concerning the employment situation of graduates in Zhejiang Province from 2010 to 2015, found that many graduates leave their jobs due to reasons such as having a major that is unsuitable for their position, a low salary, an inappropriate working environment, and dissatisfaction with one's career development prospects. Over the survey period, the graduate resignation rate rose continuously (specifically the survey found that about one-third of graduates quit their roles within three years, a phenomenon especially common among those with liberal arts majors such as economics and law). To 
counter this trend, local governments have introduced numerous employment policies to promote graduate recruitment, and universities have also created various forms of internship programmes to improve students' participation in and acceptance of internships. They have also pursued solutions such as establishing university-enterprise cooperation committees, building various internship bases which provide The actual work scene of interns, implementing the "dual tutor" system between enterprises and universities, establishing standardised management systems and regular communication mechanisms between universities and enterprises. In the past three years, the graduate survey also shows that through the IPP and the formulation of the corresponding policies detailed above, the participation of students in internships has increased significantly, the graduate resignation rate has reduced substantially and students' career sustainability has improved [23].

In terms of employers, the Zhejiang provincial government has introduced a number of policies and measures to help companies participate in the IPP, and have provided funds to subsidise internships. For example, they have provided funding to introduce innovation and entrepreneurship policies for university graduates. As a result of these measures, the willingness of enterprises to participate in the IPP has been greatly enhanced, which in turn has made the communication and cooperation mechanism between universities, government and enterprises concerning internships more efficient and harmonious. However, the graduate survey results also show that although the number of students participating in the IPP is rising, only $40 \%$ of completed internships last longer than 3 months and therefore that the programme still suffers from some significant problems. Possible reasons for these problems include: (a) many students must spend a long time looking for a job (this makes students less willing to participate in the IPP for an extended period), (b) new graduates do not have a clear idea about whether participating in the IPP will benefit their careers over the long-term. Moreover, only a few universities in Zhejiang Province, such as Zhejiang University, have implemented overseas internship programmes to broaden students' international vision and to help them acquire advanced communication skills, such as proficiency in English. Furthermore, many of the students who do participate in international IPPs do so through foreign intermediary institutions, rather than via longterm cooperation between Chinese and foreign universities. However, because the primary aim of these intermediary institutions is often to earn money this means that they tend to focus on the number of internships that they arrange rather than their quality which consequently undermines the standard and effectiveness of the international internships.

\section{Materials and Methods}

\subsection{Design of a Survey to Assess the IPP}

Different items were designed to interview students who have participated in the IPP at universities in Zhejiang Province. The survey title was "The correlation between individual employability, career sustainability and the IPP" (Table A1 in Appendix A). The survey included measures to assess students' feelings by asking them to choose suitable items relating to employability and sustainability according to the literature [24-27]. In IPP, the university will build the bridges between enterprises and students through universityenterprise cooperation committees, regularly releasing a number of internships positions and organising the students systematically into enterprises. All these could improve the students' understanding of all kinds of practice. The local government also provided some funds to intern students and enterprises. However, enterprises are required to provide a systematic internship plan, and students are required to write and hand in a systematic internship report.

In addition, a set of IPP questionnaire items were also included in the survey. Through this study, we aimed to evaluate and monitor the practical effects of the IPP and its importance to educational policy guidance. The system included the degree of IPP project completion, the degree of training target realisation, the normal operation, and the degree of sufficient funds [28]. Both qualitative and quantitative measures were used to judge the 
internship level. Every year from 2015 to 2020, 200 students and 50 employees who have participated in the IPP were chosen to provide data about the impact of the programme on their enterprise capabilities. Specifically, we wanted to evaluate the IPP's effects according to the following dimensions: (i) the definition of employability development; (ii) the advantages of the IPP; (iii) achievement of educational goals; (iv) IPP curriculum system construction; (v) where does IPP innovation need to come from; (vi) IPP mentor's training and capacity enhancement.

\subsection{Participants}

A total of 400 students from four different types of educational institutions participated in the study (half male and half female): 100 from first-class universities, 100 from provincial universities, 100 from applied colleges, and 100 from vocational colleges. The students from every group were divided into two categories. The first comprised students who had participated in the IPP. The second comprised students who had not taken part in the IPP. Those who participated in the IPP began undertaking their internships in October 2015 (T1). All survey tables were then returned in October 2020 (T2). The average age of graduates in the programme was 22 years (standard deviation 0.5). A total of 100 business executives also participated in the survey.

Prior to the survey, all students were required to complete a consent form and were asked to confirm that they would complete the survey carefully and truthfully. They were reassured that all their data would be treated confidentially.

\subsection{Data Collection and Analytical Approach}

The questionnaire used standardised words, and each respondent was asked the same questions. No arbitrary explanation or subjective questions were used in the questionnaire to avoid potential investigator bias. Furthermore, the anonymised approach used in the research was intended to mitigate psychological pressure and any possible concerns of the participants when they were answering sensitive questions.

During each interview, the interview team invited the interviewees one by one into a quiet room and asked them to focus on completing the questionnaire. Before the questionnaire survey, respondents were required to sign an informed consent form and to confirm that they would complete the questionnaire by themselves. No personal information was collected during this process. After each participant completed the survey the interviewer checked the questionnaire to make sure there were no omitted items.

The study applied SPSS to analyse the data collected from the survey. The researchers ensured that the participants had a complete understanding of the entire analysis process and that the data analysis results were verified

\section{Assessment of the Impact of the IPP on the Employability of Students}

In Zhejiang Province, China, many local businesses and governments start internships for students a year before graduation [20]. They regularly hold recruitment events at colleges and universities related to their particular industries. Such events are used to publicise the operation status of enterprises, the availability and details of internship positions, and to recruit students for management trainee positions [20]. After an internship agreement is reached between an employer and a graduate, the company will design an internship plan and quantitative goals for the candidate. The employer will also guarantee the necessary internship scholarships are available for the student. Some universities and enterprises will also jointly create a certain number of university-enterprise cooperation institutions. According to the nature of the occupational requirements of enterprises, internship equipment ensure the quality of the internship.

According to the survey report, only 30 per cent of students participated in the IPP in 2015, and only around 30 per cent of these participants completed a six-month placement. However, since then this situation has gradually improved. As Figure 1 shows the proportion of students who participated in the IPP has risen from 30\% in 2015 to 50\% 
in 2020. In terms of duration, no more than $20 \%$ of the students who participated in the internship programme did so for more than 6 months. Approximately only $10 \%$ completed an internship lasting for a period of one month.

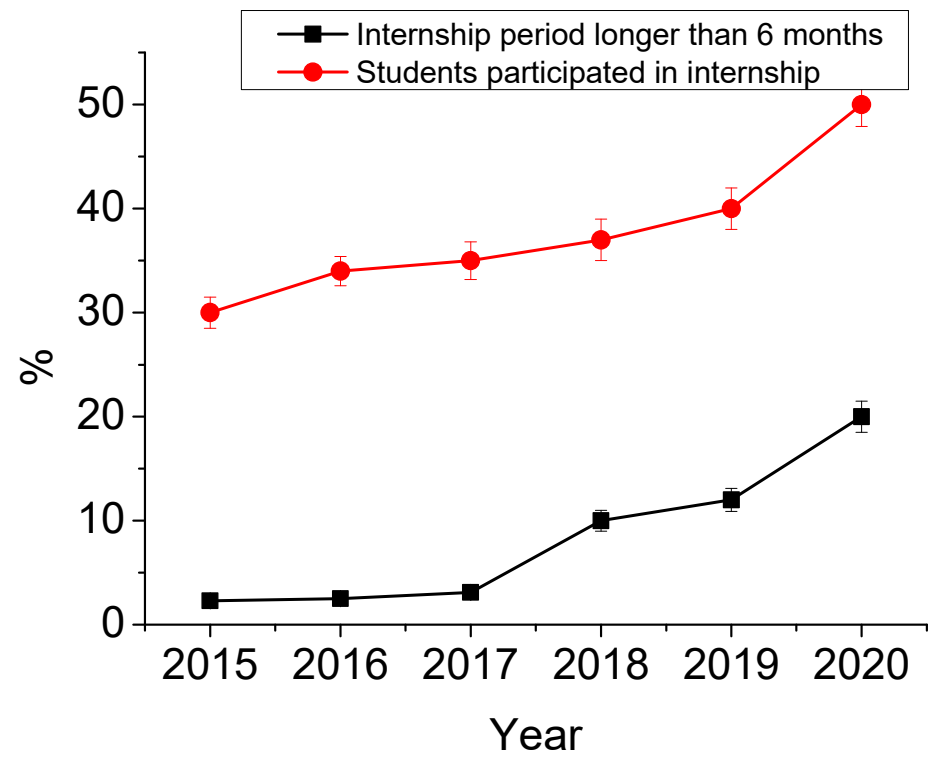

Figure 1. The number and percentage of higher education students who participated in the IPP in Zhejiang Province, 2015-2020.

\subsection{Analysis and Assessment of IPP Indices}

Based on the main survey of IPP in Zhejiang Province (2015-2020), the study has analysed the internships of students, teachers and management teams, curriculum and teaching, and the international cooperation status of 81 universities in Zhejiang Province. The overall level and individual level of the internships of colleges and universities in the province have been ranked using the internship effects. From the ranking data, it can be seen that Zhejiang University, the University of Ningbo Nottingham and Zhejiang Normal University are the top three universities with authorised master and doctoral programmes in Zhejiang Province in terms of their overall internship level. Zhejiang University of Science and Technology, Zhejiang Yuexiu Foreign Languages University and Zhejiang Police College ranked first, second and third in terms of their overall internship level among other undergraduate universities in Zhejiang Province. Zhejiang Sports Vocational College, Ningbo City Vocational and Technical College and Yiwu Industrial and Commercial Vocational and Technical College were the top three internship vocational colleges in Zhejiang Province.

As of 2020, the total number of internship programmes was 322 in all universities of Zhejiang Province. The universities have established a large number of internship places. The objective of establishing internship bases is to help students to find internship posts more easily and to accumulate internship experience and thereby to enhance their professional adaptability. Simultaneously, it is also designed to promote the major articulation of the curriculum and internships. Every year, about 130,000 students in Zhejiang are sent to these places to take part in the IPP. In the past six years, the number of IPP experts including teachers and enterprise faculties in the universities has been stable at around 5000 each year, while the number of experts with more than one year of employment and senior professional positions has been increasing by around 10\% per year. In the last year, the universities in Zhejiang Province began to revise their curricula to better incorporate the IPP. For instance, some universities have ordered all major course programmes to revise their teaching plans and to establish an internship examination system as part of their syllabus. In addition, the curriculum structure has been reformed to significantly increase 
the number of discussion classes and to provide students with a large amount of self-study time and reading lists in relation to internships.

For the students who have participated in the IPP, Table 1 shows the T test values of the IPP across the five dimensions of employability, i.e., "Innovative thinking" $(t(80)=1.15$, $\left.p<0.05, \eta^{2}=0.02\right)$, "Interpersonal communication" $\left(t(80)=0.54, p<0.05, \eta^{2}=0.07\right)$, "Problem-solving skills" $\left(t(80)=1.38, p<0.05, \eta^{2}=0.05\right)$, "Value creation" $(t(80)=0.38$, $\left.p<0.05, \eta^{2}=0.07\right)$ and "Responsibility" $\left(t(80)=1.02, p<0.05, \eta^{2}=0.05\right)$. Taken together, these findings show that the students who participated in the IPP have better skills and therefore employability than those in the non-IPP group.

Table 1. Average scores of employability between IPP and non-IPP groups.

\begin{tabular}{ccccccc}
\hline Index of Employability & \multicolumn{3}{c}{ IPP Group $\mathbf{( N = 8 0 )}$} & \multicolumn{3}{c}{ Non-IPP Group (N = 80) } \\
\hline & Average & {$[\boldsymbol{t}]$} & $\boldsymbol{\eta}^{\mathbf{2}}$ & Average & {$[\boldsymbol{t}]$} & $\boldsymbol{\eta}^{\mathbf{2}}$ \\
\hline Innovative thinking & 4.52 & 1.15 & 0.02 & 3.53 & 2.12 & 0.06 \\
Interpersonal communication & 4.21 & 0.54 & 0.02 & 3.42 & 2.32 & 1.87 \\
Problem-solving skills & 4.22 & 1.32 & 0.09 & 3.71 & 0.05 \\
Value creation & 4.23 & 1.38 & 0.07 & 3.65 & 0.05 \\
Responsibility & 4.13 & 1.02 & 0.05 & 3.65 & 1.13 & 0.04 \\
\hline
\end{tabular}

We have also assumed that the salary of graduates in their first job reflects the employment quality and the employability of students. Table 2 shows the possibility of obtaining a high salary job ( $>10,000$ Chinese yuan) by students in the IPP and non-IPP groups. The results show that the chances of the students in the IPP group (32.2\%) of attaining a high salary position were significantly higher than those in the non-IPP groups $(20.66 \%)$.

Table 2. High salary acquisition rate in IPPs.

\begin{tabular}{lcc}
\hline & $\mathbf{N}$ & $\%$ \\
\hline $\begin{array}{c}\text { \% of participants in IPP Group who } \\
\text { obtained a high salary job }\end{array}$ & 180 & 32.14 \\
$\begin{array}{c}\text { \% of participants in non-IPP Group } \\
\text { who obtained a high salary job }\end{array}$ & 120 & 20.66 \\
\hline
\end{tabular}

As for the dimensions of employability of IPP students, the $p$-value of the Chi2 test was higher than $0.1(0.234)$. The questions that participants were asked to evaluate the effectiveness of their internships are shown in Table 3. Not all students completed the questionnaire. Therefore, we only collected 320 complete responses. In total, $85 \%$ of the IPP group and $78 \%$ of the non-IPP group completed the questionnaire at the end of their internships. In order to facilitate SPSS analysis, 5-point Likert scales were used. Based on the above results, we can infer that there is a difference in employability between IPP students and non-IPP students.

Table 3 shows a bivariate analysis of the results of the student questionnaire. The data analysis reveals a clear gap between students who participated in the IPP and those who did not in terms of their job competence and their professional ability. Specifically, the data show that the variation between the groups was statistically significant. Students who participated in the IPP reported that they believed that after their internships, they had a better understanding of corporate culture, were more competent when completing important tasks, and that their professionalism had improved significantly. In addition, they reported that they had enhanced innovation and communication abilities, with a 90\% confidence level. In contrast, the results show that they were less satisfied with the salary offered by the companies in which they undertook their internships, with a confidence level of $85 \%$. 
Table 3. Student questionnaire-bivariate analysis for the IPP and non-IPP groups.

\begin{tabular}{|c|c|c|}
\hline Indices & Bivariate Analysis & $p$-Value \\
\hline $\begin{array}{c}\text { Has the internship contributed to your } \\
\text { professional development? }\end{array}$ & $\mathrm{Chi}^{2}$ & 0.020 \\
\hline $\begin{array}{l}\text { Evaluate your acceptance of the enterprise through } \\
\text { the internship }\end{array}$ & $\mathrm{Chi}^{2}$ & 0.321 \\
\hline $\begin{array}{c}\text { Evaluate the contribution of the internship to your } \\
\text { interpersonal skills }\end{array}$ & $\mathrm{Chi}^{2}$ & 0.236 \\
\hline $\begin{array}{c}\text { Evaluate the impact of the internship on your ability to } \\
\text { practice engineering in the workplace }\end{array}$ & $\mathrm{Chi}^{2}$ & 0.043 \\
\hline $\begin{array}{c}\text { Evaluate the impact of the internship on your } \\
\text { creative thinking }\end{array}$ & $\mathrm{Chi}^{2}$ & 0.032 \\
\hline $\begin{array}{c}\text { Evaluate the effectiveness of the internship in improving } \\
\text { your professionalism }\end{array}$ & $\mathrm{Chi}^{2}$ & 0.065 \\
\hline Evaluate how satisfied you are with your internship & $\mathrm{Chi}^{2}$ & 0.211 \\
\hline $\begin{array}{c}\text { Evaluate the effectiveness of the management system in } \\
\text { the internship programme }\end{array}$ & $\mathrm{Chi}^{2}$ & 0.054 \\
\hline $\begin{array}{c}\text { Evaluate how the internship will contribute to your } \\
\text { future career sustainability }\end{array}$ & $\mathrm{Chi}^{2}$ & 0.103 \\
\hline
\end{tabular}

\subsection{Validity Index and Evaluation of the Influence of the IPP}

In order to test the validity index and to evaluate the influence of the IPP on national teaching in colleges and universities, another statistical method was used. We also estimated the level of internship development of students from 81 institutions of higher education and conducted a correlation analysis between global competitiveness indices and econometric models. To better understand how IPP works it is necessary to provide a brief explanation. The Global Competitiveness Index (GCI) is a system that uses economic competitiveness to determine a company's ranking in the world. The selection of some variables i.e., execution and communication level, is explained by theoretical and empirical research [26-30], and such an index can be used to support students' sustainable development. In general, students with high employment competitiveness tend to enjoy higher salaries and benefits and have a better chance of working in Fortune 500 companies. With ongoing improvements to institutional factors, education and the quality of the workforce, it is important for students to continuously acquire new knowledge and skills during their internships if they wish to achieve the sustainable development of their individual abilities. If they fail to do so, graduates will encounter difficulties in finding high-quality and well-remunerated employment. Following analysis of the relevant data of each university and college, the authors believe that it is crucial to promote the sustainable development of students' personal abilities as indicated by the innovation and entrepreneurship index (innovative thinking), the continuous learning ability index (problem-solving, value creation) and the market competitiveness index (value creation, responsibility, problem-solving, communication) [31-34].

To establish the correlation between IPP participation and employability, we used the least square method to build a linear model. The results show that the model can accurately reflect the relationship between participation and employability. The regression equation is as follows:

$$
D_{\text {emp }}=\mathrm{b} \times D_{\text {int }}+a
$$

In the equation, $D_{e m p}$ is an estimated value of the employability indicator; $\mathrm{b}$ is the model coefficient; $D_{\text {int }}$ is the level of internship participation for the students; $a$ is a model coefficient equal to the value of $D_{\text {emp }}$ when $D_{\text {int }}=0$. The $\mathrm{b}$ factor was defined according to (2) and (3):

$$
\begin{gathered}
\mathrm{b}=\frac{\sum_{i=1}^{n}\left(D_{\text {int }}-D_{\text {clav }}\right) \times\left(D_{\text {hei }}-D_{\text {heav }}\right)}{\left.\sum_{i=1}^{n}\left(D_{\text {int }}-D_{\text {clav }}\right)^{2}\right)} \\
a=D_{\text {heav }}-b \times D_{\text {clav }}
\end{gathered}
$$


where $D_{\text {clav }}$ is the value of internship effects without participating in the IPP; $D_{\text {heav }}$ is the level of higher education development which is used in the IPP; $n=50 . b$ was set as 0.8122 , and a was 11.63 [35]. Following this, Equation (3) was revised as follows:

$$
D_{\text {emp }}=0.8122 D_{\text {int }}+11.63
$$

We further calculated the degree of participant variable $\left(D_{e m p}\right)$ on the variation of the variable $D_{\text {int }}$, and the relative factor $R^{2}$ could be calculated according to (5):

$$
R^{2}=\frac{\sum_{i=1}^{n}\left(D_{\text {heiest }}-D_{\text {heav }}\right)^{2}}{\sum_{i=1}^{n}\left(D_{\text {emp }}-D_{\text {heav }}\right)^{2}}
$$

\section{Analysis and Discussion}

On the basis of the results and data presented in Section 4, we drew a calibration curve between students' participation in the IPP and their employability in Figure 2. From this, we obtained the correlation coefficient of the regression equation $\left(R^{2}=0.8465\right)$. As $R^{2}>0.5$, the results imply that there is a strong correlation between IPP participation and students employability. In addition, we found that $54 \%$ of the change of variable $D_{\text {heiest }}$ is caused by the change of variable $D_{\text {int }}$, which indicates that all parameters set in the trend line have a good correlation degree and that the result is therefore robust.

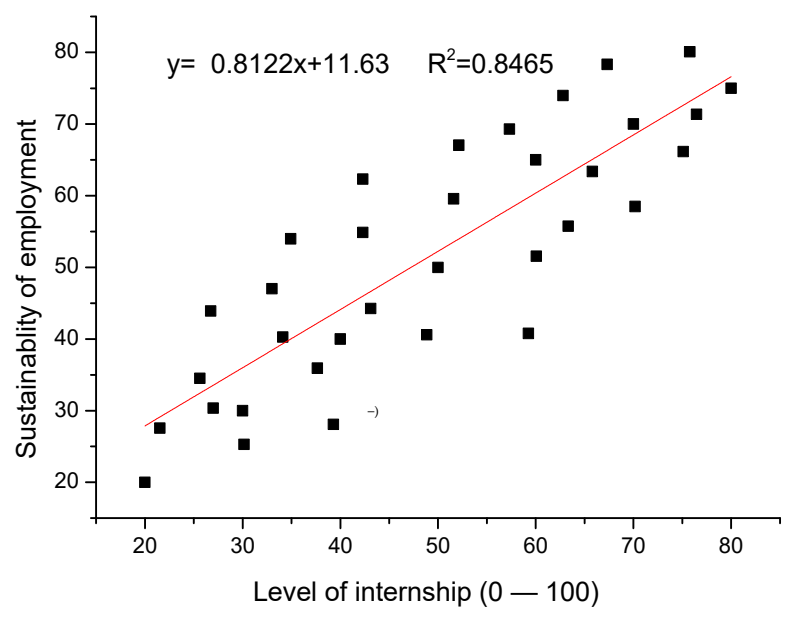

Figure 2. The dependency of the employment sustainability on the internship level after participating in the IPP.

The above analysis demonstrates that the internship development factor $D_{\text {int }}$ and the employment sustainability value $D_{e m p}$ exhibit similar dynamics. In order to further determine the correlation between the development level of the IPP and the sustainable development of higher education, we drew a calibration curve through Formula (6) and obtained the correlation coefficient:

$$
\frac{r D_{\text {int }}}{D_{\text {hei }}}=\frac{\sum_{i=1}^{n}\left(D_{\text {int }}-D_{\text {clav }}\right) \times\left(D_{\text {emp }}-D_{\text {heav }}\right)}{\sqrt{\sum_{i=1}^{n}\left(D_{\text {int }}-D_{\text {clav }}\right)^{2} \times \sum_{i=1}^{n}\left(D_{\text {emp }}-D_{\text {heav }}\right)^{2}}}
$$

It can be seen from the calculation that $r D_{\text {int }} / D_{\text {hei }}$ is equal to 0.735 . According to Quendler [36], there is a linear relationship between $r D_{i n t}$ and $D_{h e i}$, and $R^{2}$ is in the range of $0.7-0.9$. This shows that students' participation in the IPP has a significantly positive correlation with the sustainability of higher education.

The above analysis implies that the breadth and depth of both domestic and international internships are key factors to improving their higher education competitiveness. In addition, due to the causal relationship between the level of the IPP improvement 
and the level of innovation, we can say that the development level of the above indicators determines the employment quality of students from the universities and colleges in Zhejiang Province.

\subsection{Main Factors That Influence the Sustainable Development of Students' International Competence}

There are many factors that affect the sustainable development of overseas internships, including a range of economic, social, personal and other issues. For example, a student's willingness to work in a foreign country, or the difficulty they have in obtaining an overseas internship are both relevant. One of the most prominent obstacles is the language barrier faced by many students, while another relates to a lack of sufficient financial support. More than 50 colleges and universities in Zhejiang Province, as well as both the provincial and other local governments, offer financial aid to support students who study overseas or who wish to undertake internships in transnational corporations through international exchange programmes. Students can also study courses at partner universities and seek courses with English-medium instruction. Although many universities in Zhejiang Province have established good relationships with numerous German and French companies, the language barrier makes it difficult for many students to succeed in obtaining internships in Germany or France. This is because most students speak English poorly, and from a global perspective, the dominant position of English is undeniable. There is no way to actively grasp more resources and the challenge to learn how to use new technologies. In contemporary society, the wave of global information and new technologies are having a significant influence on students' attitudes to learning. It must be noted that many Chinese students now undertake internships with overseas companies, but that such internships are typically unpaid, as most companies remain unwilling to pay interns. Students who undertook placements in more than 300 overseas companies fed back data on their experiences through the website and Scopus. This data suggests that students' willingness to go abroad has been rising, and the reason for this is that there are a lot of foreign companies located in Zhejiang and they have been able to arrange overseas internships in the location of their parent companies. However, due to the pandemic, many internships have had to be undertaken online. These have a positive and lasting effect on students' mobility.

\subsection{Effects of the IPP on Students in Zhejiang Province}

According to the survey, the authors grouped the different types of internship programmes offered by various types of educational institutions into the categories depicted in Table 4.

Table 4. Internship Promotion Programme (IPP) comparison between different categories of educational institutions in Zhejiang Province.

\begin{tabular}{|c|c|c|c|c|}
\hline Categories of IPPs & First-Class Universities & $\begin{array}{l}\text { Provincial } \\
\text { Universities }\end{array}$ & Colleges & $\begin{array}{l}\text { Higher Vocational } \\
\text { Schools }\end{array}$ \\
\hline Participants & Grade 1 to 4 & 3rd year & 3rd year & 3rd year \\
\hline Term & Several months & $\begin{array}{l}\text { 4-8 weeks } \\
8-12 \text { weeks }\end{array}$ & $\begin{array}{l}\text { 4-8 weeks } \\
8-12 \text { weeks }\end{array}$ & $85 \%$ less than a month \\
\hline Participants \% & More than half & More than half & More than half & Less than $10 \%$ of students \\
\hline $\begin{array}{l}\text { Relationship with } \\
\text { employment }\end{array}$ & Strongly influenced & Prerequisite for hiring & Prerequisite for hiring & Almost non-existent \\
\hline allowance & Mostly paid & Not paid & Not paid & Not paid \\
\hline $\begin{array}{l}\text { Recent events affecting } \\
\text { internships }\end{array}$ & $\begin{array}{l}\text { Discovery of human } \\
\text { mismatch in industry }\end{array}$ & Start of tuition increase & & $\begin{array}{l}\text { Abolition of } \\
\text { recruitment agreement } \\
\text { for college graduates }\end{array}$ \\
\hline
\end{tabular}

Internships undertaken during higher education are a period of training before employment. Students are required to apply and test their theoretical knowledge in the context of real work, in order to develop their professional abilities. Williams and Lee [13] (p. 10) declared that internships can help students to deepen their relationships with one another. 
They also stated that internships can increase students' communication and cooperation skills and help them to develop relaxed personalities and strong executive abilities [13].

Williams' study [14] showed that internships reflect the connection between society and university curricula. They declared that nothing is more important than learning skills during an internship and that this is the fundamental purpose of such placements. From our study, it can be seen that the IPP strengthened the innovative thinking and the responsibilities of the participants. Munadi [15] and Leutwyler [16] also indicated that internships can increase students' cross-cultural communication skills. From our study, we also found that IPPs can help students to establish the outlook of value. In line with Lee's idea, Robson [18] also argued that there are multi-dimensional effects from participating in internships and that internships can help students to better understand themselves.

We believe that the IPP process has the biggest effect on students' communication abilities [30,35-38]. Different internship environments assist students to develop excellent communication skills. Fluent communication in English by teachers and students is particularly important [15]. From this perspective, another benefit of the IPP is to help teachers to increase their teaching capacity. Furthermore, teachers must adhere to the learner-centred results-oriented concept and build a bridge between teachers and enterprises, to help realise mutually beneficial outcomes. In the whole process of the IPP, teachers and students are deeply involved in the production practices of society and enterprises. As a result, they achieve mutual trust with enterprises [36]. Therefore, the IPP fully embodies the studentcentred concept, builds an effective communication channel between government and enterprises, and enhances the cooperative learning spirit of teachers and students [38,39].

This study has shown that participating in the IPP improves students' employability. In addition, the study has also demonstrated that the IPP enhances students' creativity, sense of social responsibility and professional quality, and leads students to develop a strong sense of shared identity with enterprises, which also makes them more willing to create value for enterprises. These outcomes are crucial in helping students to stand out in the highly competitive contemporary Chinese jobs market. The IPP can also improve students' confidence, problem-solving abilities, coordination and communication skills and leadership. Furthermore, the IPP can help students to establish a good social network and to successfully apply theoretical knowledge learned in class in real-world settings [31]. As for enterprises, they benefit from the IPP by being brought into contact with more outstanding students who may come to identify with a particular enterprise's culture through undertaking an internship at that enterprise. The dynamic and in-depth communication between the two sides can enrich both enterprises and campus culture. This kind of cross-cultural communication opens up entrepreneurial thinking and makes enterprises more willing to accept interns. Long-term and in-depth internships undoubtedly augment students' employability and their sustainable development.

\section{IPP's Important Role in Promoting Sustainability of Higher Education}

The quality of employment of university graduates will be directly related to the sustainable development of higher education. Higher education must move beyond the responsibility to prepare students to live in the world as it will be. In other words, higher education must embrace the responsibility to prepare students to shape the world in which they will live. In the context of the market economy, the fundamental driving force to promote the development of higher education is not the subjective desire of the universities, nor the administrative power of the government, but the social demand. Therefore, colleges and universities shall pay close attention to the national and regional industrial structure adjustment and social and economic development. At the same time, the universities and colleges shall make a proper investigation of the talent market demand, and take full advantage of the flexibility of running the schools and adjust the policies of the internship programme.

In the study, we can find that IPP in Zhejiang Province, aiming to follow the market and enterprise demands closely, is closely related to the market demands in terms of the arrange- 
ment of internship contents and settings of internship links. IPP can ensure that students' internship and enterprise demands are closely connected, thus enhancing students' employability. In addition to improving students' practical ability, IPP strengthens the training of students' sustainable development ability and establishes a solid communication bridge between universities and employers, which is conducive to promoting the building-up of internship places for the enterprises and enhancing employment through the internship. Therefore, it will surely promote the sustainable development of higher education.

\section{Conclusions}

The purpose of this study was to evaluate the factors that influence the employability of students from the universities and colleges which offer internships as part of their courses. To this end, we firstly designed and conducted a survey of the Internship Promotion Programme (IPP) in different universities in Zhejiang Province. Statistical data were selected and discussed throughout the study. The results showed that the IPP can promote the breadth and depth of internships. To achieve good outcomes from internships, university administrators, teachers, enterprises and students need to work together to formulate detailed and feasible plans to ensure sufficient internship time, rich and in-depth internship content, collaborative partnerships and a suitable internship programme.

The study has made three significant contributions to promoting the sustainable development of higher education. First, it confirms the IPP's value in enhancing students' employability in the aspects of innovative thinking, communication abilities (domestic and international), problem-solving skills, value creation and responsibility. Second, we have uncovered the contributory factors concerning how undertaking an internship influences the employability and sustainable development of students during the implementation of the IPP. Simultaneously, we have found that the IPP facilitates enterprises to select promising employees innovatively and competently. Finally, the IPP presents an excellent means of integrating higher education with industry. Specifically, it optimises the benefits and interests of both parties, which is in line with the national strategy in China of more effectively integrating universities with enterprises.

However, it is also important to note that there are some challenges that still affect the integration of industry and higher education. Firstly, a more stable mechanism between government, educational institutions and industry need to be established to make more flexible and reliable policies. Secondly, the participation of industry needs to be increased to provide more internship opportunities and to optimise the procedures for their implementation. Finally, there is a shortage of overseas enterprises participating in the IPP. Therefore, increasing the number of overseas enterprises and widening the international vision of students through the IPP should be the focus of future initiatives.

Author Contributions: Y.C.- draft of the article, interview and survey, polishing of English, discussion. N.G.- design of the survey, interview and survey, data collection and analysis with SPSS, revision of the article, discussion. All authors have read and agreed to the published version of the manuscript.

Funding: The Education Science Planning Project of Zhejiang Province, No.2021SCG085, Education Planning Project of Ningbo:No 2020YZD006; High-level Teaching Achievement Cultivation project of Ningbo University: No 422105453.

Institutional Review Board Statement: All subjects gave their informed consent for inclusion before they participated in the study. The study was conducted in accordance with the Declaration of Helsinki, and the protocol was approved by the Ethics Committee of the Department of Humanities and Social Sciences in Ningbo University (Project identification code: NBUHSS20210702; Approval Date: 2 July 2021).

Informed Consent Statement: Informed consent was obtained from all subjects involved in the study.

Data Availability Statement: All data needed to evaluate the conclusions in the paper may be requested from the authors. 
Conflicts of Interest: The authors declare no conflict of interest.

\section{Appendix A}

Institution: Tutors:

Name:

Major: Period:

Year:

Month:-Year: Month:

Table A1. Internship survey questionnaire.

\begin{tabular}{|c|c|c|c|c|c|}
\hline \multirow[t]{3}{*}{ No } & \multicolumn{5}{|l|}{ Items } \\
\hline & $\begin{array}{l}\text { Have you taken part in the internship } \\
\text { promotion programme? }\end{array}$ & Yes & ( ) & No & ( ) \\
\hline & Scale of evaluation & $\begin{array}{l}\text { Perfect } \\
10\end{array}$ & $\begin{array}{c}\text { Good } \\
8\end{array}$ & $\begin{array}{c}\text { Fair } \\
6\end{array}$ & $\begin{array}{c}\mathrm{Bad} \\
4\end{array}$ \\
\hline 1 & $\begin{array}{l}\text { The college has established a sound management system } \\
\text { for graduation and organises study for students }\end{array}$ & & & & \\
\hline 2 & $\begin{array}{l}\text { Do you have a copy of the internship practice guide and } \\
\text { the practice plan which need to be completed? }\end{array}$ & & & & \\
\hline 3 & $\begin{array}{l}\text { Practice guidance can combine theory with practice, the } \\
\text { guidance of teachers can solve problems in the process of } \\
\text { your internship in a timely manner }\end{array}$ & & & & \\
\hline 4 & The internship site meets the internship requirements & & & & \\
\hline 5 & The internship schedule is reasonable & & & & \\
\hline 6 & $\begin{array}{l}\text { Your ability to observe, analyse and solve practical } \\
\text { problems has improved }\end{array}$ & & & & \\
\hline 7 & $\begin{array}{l}\text { Could the necessary practical foundation be set up after } \\
\text { completing the IPP? }\end{array}$ & & & & \\
\hline 8 & $\begin{array}{l}\text { Have you improved your social communication skills? } \\
\text { Has the internship cultivated your ability to bear }\end{array}$ & & & & \\
\hline 9 & $\begin{array}{l}\text { hardship, your ability to work hard, your team-working } \\
\text { skills, and your pioneering and innovative spirit? }\end{array}$ & & & & \\
\hline 10 & $\begin{array}{l}\text { Has it helped you to understand pioneering information } \\
\text { in your professional field and the professional needs } \\
\text { of employers? }\end{array}$ & & & & \\
\hline
\end{tabular}

\section{References}

1. Pan, J.; Guan, Y.; Wu, J.; Han, L.; Zhu, F.; Fu, X.; Yu, J. The interplay of proactive personality and internship quality in Chinese university graduates' job search success: The role of career adaptability. J. Vocat. Behav. 2018, 109, 14-26. [CrossRef]

2. Kashkan, G.V.; Egorova, M.S. Problems and outlooks of international integration of higher education. Int. Educ. Stud. 2015, 8, 250-255. [CrossRef]

3. Duong, V.A.; Chua, C.S. English as a symbol of internationalization in higher education: A case study of Vietnam. High. Educ. Res. Dev. 2016, 35, 669-683. [CrossRef]

4. Valdés Montecinos, M. Internacionalización del currículouniversitario virtual en el contexto de la globalización [Internationalization of the virtual university internship in the context of globalization]. Rev. Estud. Interdiscip. Cienc. Soc. 2019, 21, 754-775.

5. De Wit, H. Internationalisation of higher education. J. Int. Stud. 2020, 10, i-iv. [CrossRef]

6. De Wit, H. The future of internationalization of higher education in challenging global contexts. ETD Educ. Temát. Digit. 2020, 22, 538-545. [CrossRef]

7. Kabeera, P. Critical analysis on the benefits and challenges of higher education internationalisation: Case of China. Mod. High Educ. Rev. 2019, 4, 86-100. [CrossRef]

8. Fragouli, E. Internationalizing the curriculum. Int. J. High. Educ. Manag. 2020, 6, 18-30. [CrossRef]

9. Zapp, M.; Lerch, J.C. Imagining the world: Conceptions and determinants of internationalization in higher education curricula worldwide. Sociol. Educ. 2020, 93, 372-392. [CrossRef]

10. Thiesen, J.D.S. Estratégias de internacionalização da educação e do currículo: Das universidadesaosterritórios da educaçãobásica [Strategies for the internship of education and internship: From universities to territories of basic education]. Educ. Policy Anal. Arch. 2019, 27, 58. [CrossRef]

11. Byram, M. Internationalisation in higher education-An internationalist perspective. Horizon 2018, 26, 148-156. [CrossRef]

12. Gaitanidis, I.; Shao-Kobayashi, S. Polarized agents of internationalization: An autoethnography of migrant faculty at a Japanese University. High. Educ. 2020, 23, 1-15. [CrossRef] 
13. Billingham, C.; Gragg, M.; Bentley, G. Internationalization: From concept to implementation. High. Learn. Res. Commun. 2013, 3, 24. [CrossRef]

14. Williams, R.D.; Lee, A. (Eds.) Internationalizing Higher Education: Critical Collaborations across the Internship; Sense Publishers: Rotterdam, The Netherlands, 2015.

15. Munadi, M. Systematizing internationalization policy of higher education in state Islamic universities. Int. J. High. Educ. 2020, 9, 96. [CrossRef]

16. Zayed, J. What can Arab EFL teachers do to assure quality in education? Int. J. Appl. Linguist. Engl. Lit. 2020, 9, 14. [CrossRef]

17. Leutwyler, B.; Popov, N.; Wolhuter, C. The Internationalization of Teacher Education: Different Contexts, Similar Challenges. In Bulgarian Comparative Education Society. Current Business and Economics Driven Discourse and Education: Perspectives from Around the World BCES Conference Books; Bulgarian Comparative Education Society: Sofia, Bulgaria, 2017; pp. 66-78.

18. Jiang, G. Exploration and Practice of Practical Teaching System of Shared Collaborative Education in Applied Universities-A case study of Z University in Zhejiang Province. Chin. J. Reforem Open. 2020, 21, 103-107.

19. Zhao, Z. The Construction and Path Analysis of Talents Training Mode of Industry-Education Integration Engineering Based on Collaborative Theory. Master's Thesis, Zhejiang University, Hangzhou, China, 2021.

20. Zhu, Q. An Empirical Study on Industrial Upgrading and the Components of College Students' Employment Ability-Based on the questionnaire survey data of 327 high technology (high-tech) enterprises Chin. J. High. Edu. Res. 2018, 5, 81-84.

21. Chen, J. From the Perspective of New and Old Kinetic Energy-The Transformation and Upgrading of Zhejiang Industry. Academic. J. Hum. Soc. Sci. 2019, 112, 22-24.

22. Fu, S.; Liu, S. Influencing Factors of Manufacturing Upgrade in Zhejiang Province Based on Global Value Chain. Appl. Mech. Mater. 2015, 755, 468-473. [CrossRef]

23. Yi, G. Impact of internship quality on entrepreneurial intentions among graduating engineering students of research universities in China. Intern. Entrep. Manag. J. 2018, 14, 1071-1087. [CrossRef]

24. Finardi, K.R.; Rojo, R.A.O. Globalization, internationalization and education: What is the connection? Int. E-J. Adv. Educ. 2015, 1, 18. [CrossRef]

25. Ji, Y. Embedding and facilitating intercultural competence development in the internationalization of the curriculum in higher education. J. Curric. Teach. 2020, 9, 13. [CrossRef]

26. Aljuwaiber, A. Knowledge strategy and leadership and their roles in change at universities. J. Manag. Strategy 2019, 11, 17. [CrossRef]

27. Benitez, M. How is academic culture influenced by internationalization? Int. High. Educ. 2019, 97, 10-12. [CrossRef]

28. Johns-Boast, L.F. What effect does an academic's concept of internationalization have on their engagement with its design and development? In Proceedings of the 2013 ASEE International Forum, Atlanta, GA, USA, 22 June 2013.

29. Niehaus, E.; Williams, L. Faculty transformation in international transformation: The role of faculty development in campus internationalization. Innov. High. Educ. 2016, 41, 59-74. [CrossRef]

30. Schuerholz-Lehr, S.; Caws, C.; Van Gyn, G.; Preece, A. Internationalizing the higher education curriculum: An emerging model for transforming faculty perspectives. Can. J. High. Educ. 2007, 37, 67-94. [CrossRef]

31. Yin, D.R.K. Case Study Research and Applications: Design and Methods, 6th ed.; SAGE Publications, Inc.: Los Angeles, CA, USA, 2017; ISBN 978-1-5063-3616-9.

32. Fourati-Jamoussi, F.; Dubois, M.J.F.; Agnès, M.; Leroux, V.; Sauvée, L. Sustainable Development as a Driver for Educational Innovation in an Engineering School: The Case of UniLaSalle. Eur. J. Eng. Educ. 2019, 44, 570-588. [CrossRef]

33. Fourati-Jamoussi, F.; Dubois, M.J.F.; Chedru, M. Teaching Sustainable Development and Innovation in Engineering Education: Students' perception. In Proceedings of the SEFI Annual Conference, Copenhagen, Denmark, 17-21 September 2018.

34. Kopnina, H.; Cocis, A. Environmental Education: Reflecting on Application of Environmental Attitudes Measuring Scale in Higher Education Students. Educ. Sci. 2017, 7, 69. [CrossRef]

35. Moreno-Guerrero, A.-J.; Soler-Costa, R.; Marín-Marín, J.-A.; López-Belmonte, J. Flipped learning and good teaching practices in secondary education. Comun. Rev. Cient. Comun. Educ. 2021, 29, 103-113. [CrossRef]

36. Quendler, E. Sustainable development in education: Are we ready for change? System innovation and higher education in life sciences. In Agro Ecological Transitions: Changes and Breakthroughs in the Making; Wageningen University \& Research: Wageningen, The Netherlands, 2017; pp. 195-212.

37. Leask, B. Internationalizing the Curriculum; Routledge: London, UK, 2015.

38. Fourati-Jamoussi, F.; Agnès, M.; Dubois, M.J.F.; Leroux, V.; Rakotonandraina, N.; Kotbi, G.; Sauvée, L. How to Promote, Support and Experiment Sustainability in Higher Education Institutions? The Case of LaSalle Beauvais in France. Int. J. Innov. Sustain. Dev. 2015, 9, 227-245. [CrossRef]

39. Fourati, F.; Dubois, M.J.F.; Agnès, M.; Leroux, V.; Kotbi, G.; Sauvée, L. Former des élèvesingénieurs au développementdurableUnea pproche par et pour l'innovationpédagogique à LaSalle Beauvais. In Création, Créativité et Innovation Dans la Formation et L'Activité D’Ingénieur; UTBM: Montbéliard, France, 2017; pp. 229-237. ISBN 979-10-91901-24-6. 